not significant. It is interesting to note that the prediction of this particular effect was based on the specificity hypothesis (Young, 1962) that the $I$ functions as the effective stimulus for the Fl. Consequently, the present findings on FIs suggested that learning in accordance with the specificity hypothesis occurs in the middle, or at least the isolation manipulation alters the use of the position the item holds as the effective stimulus.

\section{REFERENCES}

BONE, R. N., \& GOULET, L. R. Serial position and the von Restorff isolation effect. Joumal of Experimental Psychology, 1968, 76, 494-496.

GIBSON, E. J. A systematic application of the concepts of generalization and differentiation to verbal learning. Psychological Review, 1940, 47, 196-229.

GLAZE, J. A. The association value of nonsense syllables. Journal of Genetic Psychology, $1928,35,255-269$.

GREEN, R. T. Surprise as a factor in the von Restorff effect. Journal of Experimental Psychology, 1956, 52, 340-344.

JENKINS, W. O., \& POSTMAN, L. Isolation and spread of effect in serial learning. American Journal of Psychology. 1948, 61, 214-221.

JENSEN, A. R. The von Restorff isolation effect with minimal response leaming. Journal of Experimental Psychology, 1962, 64, 123.125.

MOCRARY, J. W., JR., \& HUNTER, W. S. Serial position curves in verbal learning. Science, 1953, 117, 131-134.

MCLAUGHLIN, J. P. The von Restorff effect in serial leaming: Serial position of the isolate and length of list. Journal of Experimental Psychology, 1966, 72, 603-609.

NEWMAN, S. E., \& SALTZ, E. Isolation effects: Stimulus and response generalization as explanatory concepts. Joumal of Experimental Psychology, 1958, 55, 467-472.

PILlSBURY, W. B., \& RAUSH, H. L. An extension of the Kohler-Restorff inhibition phenomenon. American Journal of Psychology, 1943, 56, 293-298.

SALTZ, E., \& NEWMAN, S.E. The von Restorff isolation effect: Test of the intralist association assumption. Journal of Experimental Psychology, 1959, 58, 445-451.

STEIL, P, \& HYNUM, L. The von Restorff isolation effect with one and three isolates. Psychological Reports, in press.

von RESTORFF, H. Cited by K. Koffka. Principles of Gestalt psychology. New York: Harcourt, Brace, \& World, 1935.

YOUNG, R. K. Tests of three hypotheses about the effective stimulus in serial learning. Journal of Experimental Psychology, 1962, 63, 307-313.

\title{
Racial meaning with a mediated generalization procedure*
}

\author{
NORMAN H. HAMM \\ University of Nebraska at Omaha, Omaha, Nebr. 68101 \\ WILIAM L. JOHNSON \\ Creighton University, Omaha, Nebr. 68131 \\ and \\ PATRICIA S. MULLANEY \\ University of Colorado, Boulder, Colo. 80302
}

Seventy-ight white and black college Ss, divided equally into white, Negro, and control mediation groups, were tested for generalized responses along a color dimension ranging from medium brown to light tan. Control (no racial meaning implied) and mediational (racial meaning implied) gradients were derived with five colors, two lighter and two darker than the CS. On the control gradient, (1) Ss generalized more to lighter colors than to darker colors, and (2) black Ss generalized more to darker colors and less to lighter colors than did white Ss. No significant mediation or Race by Mediation effect was found.

The techniques available for studying stimulus generalization may be used to investigate perceptual processes. Despite their frequent use in learning studies, particularly those concerned with stimulus control, these techniques have not been applied to the problem of person and racial perception. The present investigation was undertaken to study the skin color perception of white and black Ss with a human stimulus-generalization procedure. A specially constructed color dimension which resembled Negroid flesh tones was used for this purpose. In addition, semantic generalization was investigated by deriving both control (no racial meaning implied) and mediated (racial meaning implied) gradients. Several studies have shown that the generalization of a voluntary finger-lift response to a monochromatic stimulus is influenced by the mediational effect of color labeling (Thomas \& Bistey, 1964; Thomas \& Decapito, 1966). These studies would predict that there would be increased generalized responding to

*The authors are indebted to Professors David $R$. Thomas and Kenneth $L$. Hoving for suggesting the technique used in this investigation. A version of this paper was presented at the meeting of the Midwestern Psychological Association, Cincinnati, Ohio, April 1970. colors that were appropriate to the label (e.g., darker colors for Ss given a "Negro" label) and reduced generalized responding to stimuli for which the label was inappropriate.

\section{SUBJECTS}

The Ss were 39 black and 39 white callege students from the University of Nebraska at Omaha. Thirteen Ss from each race composed the white, Negro, and control mediation groups described below. APPARATUS

Ss were tested for generalization with a $2 \times 5 \mathrm{ft}$ perceptual alley, constructed from black cloth and divided into two sections, a right- and a left-hand alley. The manipulandum was a modified telegraph key mounted beneath the alley. The key was wired so that its release activated a signal light to the $E$, thus signifying a response.

The stimuli consisted of five colors painted on 6-in. square cards. The series was constructed from a base mixture of acrylic (polymer emulsion) paint consisting of two parts burnt umber mixed with one part raw siena. Ten grams of base were mixed with $2,4,6,8$, and $10 \mathrm{~g}$ of white paint to yield five different colors ranging from medium brown to light tan. The intermediate color served as the CS.

PROCEDURE AND CONDITIONS

Two gradients were derived for each $S$. For each gradient the standard 
Table 1

Experimental Design

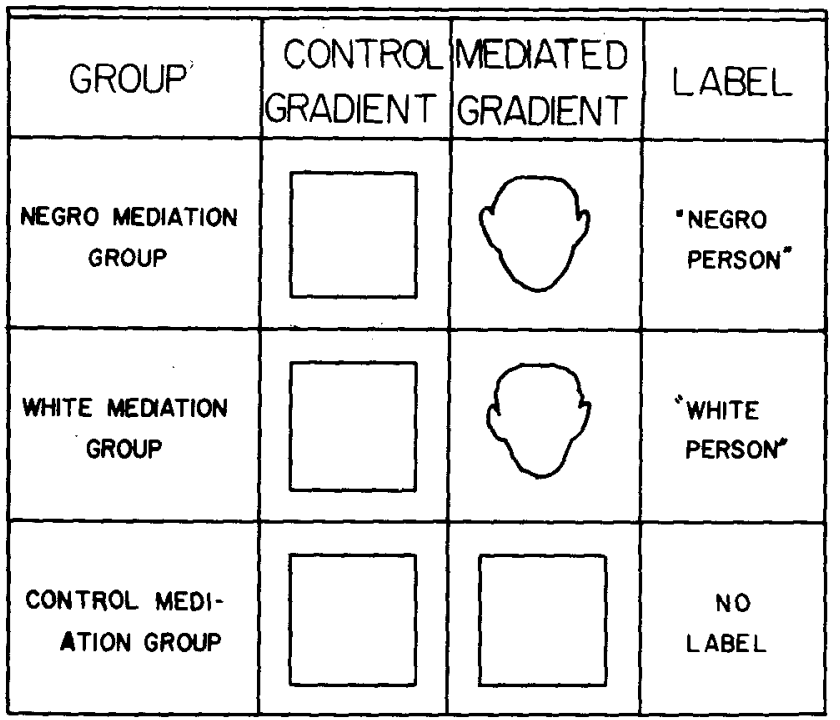

generalization instructions were given to the Ss (see Kalish, 1958). Following a $30-$ sec presentation of the CS, eight randomized series of five test stimuli, including the CS, were presented. Each test stimulus was presented for a period of $5 \mathrm{sec}$ and was followed by a 5 - to $10-\mathrm{sec}$ intertrial interval, which allowed the $E$ to record the presence or absence of a response and to choose the next stimulus.

Table 1 presents graphically the design of the study. Control gradients were derived by presenting the colors, superimposed over a 4-in. square hole at the end of the right-hand alley. A second gradient was derived for the Negro and white mediation groups by presenting the

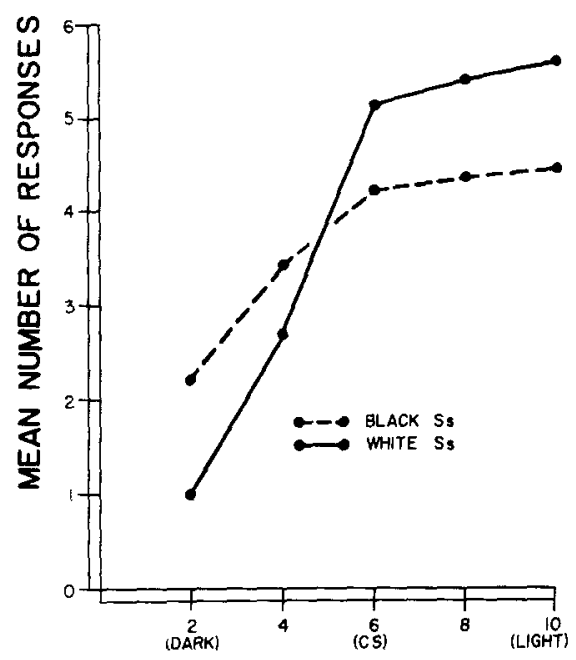

GRAMS OF WHITE PAINT

Fig. 1. Mean control generalization gradients for black and white $S s$ on five skin colors. colors down the left-hand alley through a template cut out to respresent a face. The standard generalization instructions were modified (see Thomas \& Decapito, 1966) so that the Negro mediation group was told by E that the CS was the face of a Negro person (e.g., "most people think this is a face of a Negro"), and the white mediation group was told that the CS was the face of a white person. To assess practice effects, a second gradient was derived from the control mediation group without the $\mathrm{E}$ attributing a racial label to the CS. For this group the colors were presented through a square hole at the end of the left-hand alley.

\section{RESULTS AND DISCUSSION}

Figure 1 presents the control gradients for black and white Ss on five colors. A $t$ test compared the number of generalized responses to colors lighter than the CS with the number of generalized responses to colors darker than the CS. The significant $t(1,77)=5.92, p<.01$, indicated that Ss generalized more to lighter colors than to darker ones. While this finding is consistent with the results of investigations which have studied generalization along a stimulus-intensity dimension (see Razan, 1949), it may not be a rigorous demonstration of the effect since no attempt was made to scale the stimuli with psychophysical methods.

A second measure of generalization was calculated by subtracting the number of generalized errors to lighter cofors than the CS from the number of generalized errors to darker colors than the CS. This measure indicated the relative darkness of $S$ errors. These data were subjected to a t test and an overall 2 (race) by 3 (condition) by 2 (gradient) analysis of variance. The latter analysis indicated the absence of a significant mediation or Race by Mediation effect.

The significant $t(1,38)=2.21, p<.025$, indicated that on the control gradient black Ss generalized more to darker tones and less to lighter tones than did white Ss (see Fig. 1). Unfortunately, while intriguing, this racial difference is difficult to explain. Since in real life black Ss have had more differential experience with the darker colors used in the stimulus sequence, it might be predicted from the Lashley-Wade hypothesis (1946) that they would generalize less to darker colors than white Ss. However, the very opposite racial difference was found.

The talure to find a racial difference consistent with the Lashley-Wade hypothesis might be taken as support for the notion that generalized errors in the present experiment indicate Ss' preferences for certain skin colors. Given this assumption, the reported racial difference appears consistent with the identification theory (black Ss favor darker skin colors) but appears inconsistent with severa] studies which have shown that black Ss ascribe a negative value to dark skin colors (Clark \& Clark, 1950; Morland, 1966; Stevenson \& Stewart, 1958). Perhaps this inconsistency means that young black college Ss prefer dark skin colors. In this connection, it might be mentioned that almost all of the black Ss used in the experiment belonged to the B.L.A.C. (Black Liberators for Action on Campus) organization. Additional research should be done to verify the preceding suggestion.

\section{REFERENCES}

CLARK, K, B., \& CLARK, M. K. Emotional factors in racial identification and preference in Negro children. Journal of Negro Education, 1950, 19, 341-350.

KALISH, H. I. The relationship between discriminability and generalization: $A$ reevaluation. Joutnal of Experimental Psychology, 1958, 55, 638-644.

LASHLEY, K. S., \& WADE, M. The Pavlovian theory of generalization. Psychological Review, 1946, 53, 72-87.

MORLAND, J. K. A comparison of race awareness in Northern and Southern children. American Journal of Orthopsychiatry, 1966, $36,22-31$.

RAZRAN, G. Stimulus generalization of conditioned responses. Psychological Bulletin, $1949,46,337-365$.

STEVENSON, H. W., \& STEWART, E. C. A developmental study of racial awareness in young children. Child Development, 1958, 29, $400-409$.

THOMAS, D. R., \& BISTEY, G. Stimulus generalization as a function of the number and range of generalization test stimuli. Journal of Experimental Psychology, 1964, 68, 599-602.

THOMAS, D. R., \& DECAPITO, A. Role of stimulus labeling in stimulus generalization. Journal of Experimental Psychology, 1966, 71, 913-915. 